Post print

Courouau, J. L., et J. C. Robin. « Chemistry control analysis of lead alloys systems to be used as nuclear coolant or spallation target ». Journal of Nuclear Materials 335, n 2 (2004): 264.

https://doi.org/10.1016/j.jnucmat.2004.07.022

\title{
Chemistry control analysis of lead alloys systems to be used as nuclear coolant or spallation target.
}

\author{
J-L. COUROUAU*, J-C. ROBIN
}

Commissariat à l'Energie Atomique (CEA), Centre d'étude de Cadarache,

13108 Saint-Paul-Lez-Durance cedex, France

*Corresponding author:

J-L. COUROUAU

CEA Cadarache

DEN/DER/STR/LCEP

F-13108 Saint-Paul-Lez-Durance cedex

Tel.: +33-4 42253266

Fax: +33-4 42257287

e-mail: jean-louis.courouau@cea.fr

Subject codes : 101 (impurities) ; C04 (chemical reactions) ; L03 (liquid metals) ; M08 (monitoring methods) 
Post print

Courouau, J. L., et J. C. Robin. « Chemistry control analysis of lead alloys systems to be used as nuclear coolant or spallation target ». Journal of Nuclear Materials 335, no 2 (2004): 264.

https://doi.org/10.1016/j.jnucmat.2004.07.022

\section{Abstract}

This study presents the lead alloy system chemistry analysis for use as nuclear coolant or spallation target in ADS related systems in order to set down the needs for purification processes and monitoring. The study is limited here to the 2 main impurities, oxygen and iron. The analysis of the various potential pollution sources that may occur during the various operating modes is given, as well as a first pollution rate assessment. In order to limit the consequences in term of contamination (clogging) and corrosion, it is necessary to define specifications for operation as regards oxygen and iron content in the fluid. As iron cannot be measured and controlled up to now, the best specification is to set the oxygen as high as possible, defined by the cold leg interface temperature to ensure tolerable contamination, in order to maximize the oxidation area to ensure corrosion protection by self-healing oxide layer for the entire system.

\section{Introduction}

The chemistry of the lead alloys, liquid lead-bismuth eutectic (LBE) or pure lead, is a critical issue for its use as a coolant in nuclear systems or as liquid spallation target for the high neutrons source of an accelerator driven system (ADS), which are foreseen for nuclear waste transmutation [1] [2] [3] [4]. In particular, oxygen and iron are the main impurities playing a key role in the definition of the chemical specifications required for the design and the operation as regards the active control and monitoring. This is why the focus is made only on these 2 main impurities for the sake of simplicity. Oxygen and iron are involved in the contamination of the liquid system by lead, bismuth and iron oxides or even pure iron. This has to be avoided in any case to ensure reliable and safe operation on the long term, as this can affect the ability of the fluid to flow and to extract the heat by clogging into pipes or narrow areas, or by depositing on the heat exchanger surfaces. The second requirement is to ensure an efficient corrosion protection of the structural materials that depends on both oxygen and iron for the oxide layer self-healing method that is chosen for this study.

The objective of this paper is first to investigate the various pollution sources in the system for both oxygen and iron and to assess their foreseeable behaviors during the various operating modes. Then it is possible to derive chemical specifications to ensure both contamination and corrosion control, as well as to define the basic requirements in terms of monitoring and processes required to operate a nuclear system.

\section{Oxygen and iron release rates}

Pollution sources can occur under various operating modes, from the start-up to the shutdown for maintenance. Although the sources are often referring to trace contaminants, they can have a macroscopic effect on the operation. The large liquid sodium reactor experience allows identifying the various pollution sources that could be expected in a liquid metal system, as well as giving some figures [5] as very few data are available [6].

The start-up operation as well as the maintenance operations with the opening of the circuit represent almost the only source of pollution with oxygen: filling operation, new structure out gassing, and air inlet reacting with residual alloys.

Depending on the filling and transfer operations, the lead alloys can be assumed to be saturated in oxygen, which represents the base line for assessing the initial quantity of oxygen introduced in the systems. In order to limit this to a minimum, the transfer temperature is set 
Post print

Courouau, J. L., et J. C. Robin. "Chemistry control analysis of lead alloys systems to be used as nuclear coolant or spallation target ». Journal of Nuclear Materials 335, no 2 (2004): 264.

https://doi.org/10.1016/j.jnucmat.2004.07.022

at the lowest achievable value to take advantage of the lower solubility: $200^{\circ} \mathrm{C}$ for LBE for instance corresponds to a solubility of $0.01 \mu \mathrm{g} / \mathrm{g}$ (wt-ppm) of oxygen according to the "Orlov" relation [6] [7]. Filtration or piping by the bottom allow ensuring that only dissolved oxygen enters the system by keeping the coolant oxides as well as other slag's in the filling tank. If a chemical control process (reduction by hydrogen, gas and liquid monitoring) is applied during this operation the amount of oxygen can be significantly decreased. In particular the occurrence of air pollution during this operation should be detected and compensated for.

New structures such as new fuel elements, heat exchanger, etc., wetted with the liquid metal will release gases adsorbed on the surface, such as moisture and hydrogen. The release into liquid sodium becomes significant at $250-300^{\circ} \mathrm{C}$, increases slightly up to the normal operating temperature, and, even though, lasts for days. The total amount of released gases in sodium was accurately measured for $316 \mathrm{~L}$ alloy: $1.3 \mathrm{~g}(\mathrm{O}) / \mathrm{m}^{2}$ and $0.15 \mathrm{~g}(\mathrm{H}) / \mathrm{m}^{2}$ [5]. The net oxygen pollution ratio, assuming that oxygen is recombined with hydrogen to form water is then 0.1 $\mathrm{g} / \mathrm{m}^{2}$. Considering the large surface developed by the fuel cladding as well as by the heat exchanger, this pollution could not negligible. However, the actual release rate for structure wetted by lead alloys is to be measured. Indeed, the oxide layer growth will use some of this oxygen.

The loss of tightness of the circuit during maintenance with air ingress reacting with the residual layer of liquid metal should not be neglected as well. Despite the careful and heavy procedures applied, this pollution is almost always observed at PHENIX (France) for instance [5]. After each repairing on the secondary loops, the pollution related to this poor air tightness is always large and requires a specific purification procedure. It is known [7] that this represents the pollution source at the origin of the early failures of the first 2 Russian LBE reactors: land reactor KV-27 and project 645 submarine, leading to the gradual accumulation of coolant oxide in the system and ending in a critical contamination issue.

During normal operation, the oxygen pollution sources are cover gas renewal, which is negligible, or leaks from the steam generator (SG), which are difficult to assess. Indeed, SG can be designed for a null leak rate, as it was done for the sodium cooled reactor. However, a small leak rate allowance decreases drastically the constraints for design and operation: for instance, a typical leak rate for the pressurized water reactor SG lies between 0 and $5 \mathrm{l} / \mathrm{h}$, with a shutdown threshold set at $70 \mathrm{l} / \mathrm{h}$. In the case of the use of lead alloy as the cooling medium of a reactor system, steam will transfer to the gas phase system because of the pressure gradient. There, it will oxidize the lead alloy with time [6] as well as it will transfer to the cover gas. The actual oxidation rate is to be measured in representative operating conditions.

However, the hydrogen is continuously produced during normal operation and will reduce the dissolved oxygen. The diffusion source from the $\mathrm{SG}$ is due to the aqueous corrosion that generates atomic hydrogen at the steel interface as well as to the hydrazine $\left(\mathrm{N}_{2} \mathrm{H}_{4}\right)$ thermal decomposition. Indeed, hydrazine is added in excess to the water/steam circuit to limit the corrosion. For illustration the hydrogen diffusion rate was the main pollution source of the secondary circuits in sodium fast reactors. Release rates from 0.07 to $0.14 \mathrm{~g}(\mathrm{H}) / \mathrm{m}^{2} / \mathrm{h}$ have been measured for inconel 800 [5], slightly decreasing with operating time due to the magnetite layer growing on the water side. However, the real effect of coating or oxide layer on the lead alloys side may reduce drastically this rate, so that actual hydrogen diffusion rates have to be measured for relevant material of lead alloys systems. 


\section{Post print}

Courouau, J. L., et J. C. Robin. « Chemistry control analysis of lead alloys systems to be used as nuclear coolant or spallation target ». Journal of Nuclear Materials 335, no 2 (2004): 264.

https://doi.org/10.1016/j.jnucmat.2004.07.022

The hydrogen rate coming from the proton beam and from the spallation and fission production is up to now poorly known, but it could amount to several liters per year of operation. Ternary fission accounts for roughly one hydrogen atom yielded every 10000 fast fissions, which represents roughly $0.04 \mathrm{~g}(\mathrm{H}) / \mathrm{h}$ and $0.5 \mathrm{TBq} / \mathrm{d}$ of tritium for a BREST-300 like reactor $(700 \mathrm{MW})[8]$. Their actual release from the fuel is to be assessed. Almost 100\% release to the coolant was observed in sodium fast reactors.

Another potential source of oxygen consumption during normal operation is the oxygen used to maintain an oxide corrosion protection layer based on the magnetite. This consumption rate related to the oxide layer growth is assessed to be $9.10^{-4} \mathrm{~g} / \mathrm{m}^{2} / \mathrm{h}$ at $500^{\circ} \mathrm{C}$ [6]. In addition, the spallation products will consume oxygen continuously by forming more stable oxides but this effect is assumed to be limited. This contributes to reduce the dissolved oxygen during normal operation to very low level, assuming that the SG leak rate is negligible.

An incidental source of oxygen pollution must be cited as well such as the loss of tightness of the gas system leading to air inlet. Such incident happened several times in sodium reactors (SUPERPHENIX 1990), even if the early detection system has been improved since then to limit the pollution by implementing gas chromatography for nitrogen monitoring in the cover gas.

The source of iron in the liquid metal system is the corrosion of the structural materials. The release rate is function of the operating temperature, the temperature gradient, the fluid velocity, the corrosion protection policy, the oxygen content and the material itself, without being exhaustive. Up to now, none of these points is specified for a demonstration ADS, so that only illustrating figures can be given. In case of a coating protection, which can be a selfhealing oxide layer $\left(\mathrm{Fe}_{3} \mathrm{O}_{4}+\left(\mathrm{Fe}_{\mathrm{x}} \mathrm{Cr}_{1-\mathrm{x}}\right)_{3} \mathrm{O}_{4}+\mathrm{Cr}_{2} \mathrm{O}_{3}\right)$, or alumina coating deposited by pack cementation or any other method, the iron dissolution from the base material into the liquid metal is limited by the mass transfer throughout this coating, acting as an iron diffusion barrier that represents the working mechanism of the corrosion protection. In any case the iron release rate will not be null. In addition, for the self-healing oxide process, which requires a controlled oxygen activity, the iron release rate depends on the competition between the oxide layer growth at the metal/oxide interface and the slight oxide layer reduction at the liquid metal interface (erosion, friction). For a BREST-300 like reactor configuration, the release rate can be assessed to $0.8 \mathrm{mg}(\mathrm{Fe}) / \mathrm{m}^{2} / \mathrm{h}$ at $500^{\circ} \mathrm{C}$ for EP823 Russian steel for a controlled mean oxygen activity in the range of $10^{-2}$ to $10^{-4}$ [6]. As the surface developed by the core and heat exchanger is large, the yearly release amounts to the kilogram range for the coolant loop.

If no oxygen control is applied, the structure operates in the dissolution regime, as the oxygen is expected at a very low level. Uniform dissolution is foreseen, at least for the hot leg section. Supposing a $20 \mu \mathrm{m} / \mathrm{y}$ decrease $(10 \%$ thickness for fuel clad of $1.2 \mathrm{~mm}$ whose operating life is 6 years), the release rate of iron into the liquid metal amounts to tens of kilograms for the coolant loop of the BREST-300 like reactor. This source term is not negligible, as it is one order of magnitude higher than the source expected when a self-healing layer is present, and as it is involved in a mass transfer process from the hot leg (dissolution) to the cold leg (deposition) either in oxidized form or metallic form, as dissolved metals or as particles (metal or oxide). Deposits on the heat exchanger decrease the heat transfer, thus the heat removal capacity of the system. In addition, the amounts involved are high enough to present some contamination issue, if the deposits accumulate preferentially in a cold spot having a narrow area. Considering a pool type reactor and the relative buoyancy of the oxide, they may accumulate as well at the gas-liquid interface, being a cold point of the system, leading to 
Post print

Courouau, J. L., et J. C. Robin. "Chemistry control analysis of lead alloys systems to be used as nuclear coolant or spallation target ». Journal of Nuclear Materials 335, no 2 (2004): 264.

https://doi.org/10.1016/j.jnucmat.2004.07.022

other operational problems. During transient condition such as the shutdown procedure, a rapid re-distribution of the impurities can be predicted. This was observed in a matter of a few hours on the CICLAD LBE loop [9] during a hot isothermal operation: a rapid dissolution was observed, followed by a rapid crystallization in the new coldest point which was the electromagnetic pump duct that eventually clogged completely.

These phenomena are usually observed in a pressured water reactor as well in sodium reactor, but the quantities involved are order of magnitudes lower, so that the main concern is related to the distribution of the activated corrosion products for assessing dose rates for maintenance rather than a real contamination (clogging) issue.

\section{Specifications for coolant or target loops}

The first specification is related to the contamination issue: ensure in any part of the system as well as in any operating condition that the conditions for the formation of coolant oxides are not fulfilled. As the most stable coolant oxide is the lead monoxide, $\mathrm{PbO}$, compared to the other potential oxides $\left(\mathrm{PbO}_{2}, \mathrm{~Pb}_{3} \mathrm{O}_{4}, \mathrm{Bi}_{2} \mathrm{O}_{3}\right)$, the solubility of this oxide defines the maximum allowable oxygen chemical concentration $\left(\mathrm{Co}^{*}\right)$ [7] [10]:

$$
\begin{aligned}
& \text { Lead : } \log C_{o(w g t \%)}^{*}=3.2-\frac{5000}{T_{(K)}} \text { for } 400^{\circ} \mathrm{C}<\mathrm{T}<700^{\circ} \mathrm{C} \\
& \text { LBE : } \log C_{o(w g t \%)}^{*}=1.2-\frac{3400}{T_{(K)}} \text { for } 400^{\circ} \mathrm{C}<\mathrm{T}<700^{\circ} \mathrm{C}
\end{aligned}
$$

Considering solid lead monoxide as the standard state for the oxygen in lead-bismuth eutectic, the oxygen activity shall be equal to unity when saturation is reached. Assuming the Henry's law to be valid, the activity of oxygen is given by the ratio of the oxygen concentration, $\mathrm{C}_{0}$, to the solubility, $\mathrm{C}_{\mathrm{o}}{ }^{*},\left(\mathrm{a}_{\mathrm{o}}=\mathrm{C}_{\mathrm{o}} / \mathrm{C}_{\mathrm{o}}{ }^{*}\right)[11]$. The operating specification to avoid any contamination of the coolant is then: $\mathrm{a}_{\mathrm{o}}<1$ or $\mathrm{C}_{\mathrm{o}}<\mathrm{C}_{\mathrm{o}}{ }^{*}$ for all operating temperatures in any point of the loop, both in the liquid bulk and at the wall interface. Compared to liquid sodium, the oxide formation threshold is rather low as the oxygen solubility in LBE is 100 to 1000 times lower at relevant operating temperatures.

Assuming that the corrosion protection is ensured by self-healing oxide layer, the second specification is then related to its stability: ensure in any part of the system, both in the liquid bulk and at the wall interface, and for any operating condition that the conditions for the formation of iron oxide are fulfilled. Indeed, the magnetite being the least stable oxide of the layer, it defines the minimum allowable oxygen concentration. The reaction of the steel oxidation in liquid lead alloys is as follows:

$$
\frac{3}{4} \mathrm{Fe}_{(\text {dissolved })}+\mathrm{PbO}_{(\text {dissolved })} \longrightarrow \frac{1}{4} \mathrm{Fe}_{3} \mathrm{O}_{4}+\mathrm{Pb}_{(\text {liquid })}
$$

Where oxygen is supposed in solution in the form of dissolved $\mathrm{PbO}$ under its saturation limit. This is equivalent to consider that a cloud of $\mathrm{Pb}$ atoms surrounds the $\mathrm{O}$ atom. Dissolved oxygen chemical activity is then referring to dissolved $\mathrm{PbO}$ activity. Computed with the help of the HSC database [12] for the limited but relevant temperature range of $400 \mathrm{~K}-1000 \mathrm{~K}$, the standard free enthalpy of reaction (3) is then:

$$
\Delta_{r} G^{o}(J / \mathrm{mol})=-57690-21.1 \cdot T_{(K)}
$$


Post print

Courouau, J. L., et J. C. Robin. "Chemistry control analysis of lead alloys systems to be used as nuclear coolant or spallation target ». Journal of Nuclear Materials 335, no 2 (2004): 264.

https://doi.org/10.1016/j.jnucmat.2004.07.022

Lead activity is equal to unity in pure lead coolant, whereas the following Russian relation is given for lead activity in LBE, which has been recalled in [4]:

$\ln a_{P b}=-\frac{135.21}{T_{(K)}}-0.8598$

The iron solubility in lead or lead alloys is expressed as [6] [7]:

Lead : $\log C_{F e(w g t \%)}^{s}=0.34-\frac{3450}{T_{(K)}}$

$\mathrm{LBE}: \log C_{\mathrm{Fe}(\mathrm{wgt} \%)}^{s}=2.01-\frac{4380}{T_{(K)}}$

The activity product of the reaction of formation of magnetite in lead alloys is then as follows for equilibrium conditions:

$\ln \left(a_{O} \cdot a_{F e}^{3 / 4}\right)=\ln a_{P b}+\frac{\Delta_{r} G^{o}}{R T}$

Defining the iron activity similarly to the oxygen activity, $\mathrm{a}_{\mathrm{Fe}}=\mathrm{C}_{\mathrm{Fe}} / \mathrm{C}_{\mathrm{Fe}}{ }^{*}$, it is equal to one when the iron is saturated in the solution, and defining the minimum oxygen concentration required for effective corrosion protection, $\mathrm{C}_{\mathrm{o}} \mathrm{min}$, the following relations are derived :

Lead : $\log C_{O \min (\%)}=-\frac{3}{4} \log C_{F e(\%)}+2.355-\frac{10600}{T_{(K)}}$

LBE $: \log C_{O \min (\%)}=-\frac{3}{4} \log C_{F e(\%)}+1.2375-\frac{9757}{T_{(K)}}$

The oxygen concentration areas of operation to ensure both no contamination and corrosion protection $\left(\mathrm{C}_{\text {omin }}<\mathrm{C}_{0}<\mathrm{C}_{\mathrm{o}}{ }^{*}\right)$ are almost similar for the liquid lead or the lead-bismuth eutectic. Then, the operating specifications for oxygen can be evaluated from Figure 1, where the minimum oxygen concentration required for ensuring oxide layer stability is plotted for saturated iron content, which maximizes the oxidation area as for lower iron concentration the minimum oxygen concentration increases. For an isothermal system, a vertical line plotted at the system temperature defines the oxygen range that is allowed: as illustrated in Figure 1, a system operating at $420^{\circ} \mathrm{C}$ is giving an oxygen range of $2.510^{-6}$ to 2 wt-ppm. In principle, for a non-isothermal system, the intersection of the two ranges defined by the vertical lines plotted respectively for the cold and the hot leg temperatures is defining the oxygen range. As illustrated in Figure 1, a system operating between $420^{\circ} \mathrm{C}$ and $540^{\circ} \mathrm{C}$ is giving an oxygen range of $610^{-5}$ to 2 wt-ppm.

For non-isothermal system, the temperature at the interface is different from the bulk temperature because of the heat transfer process. However, if the oxide layer protection is required, the minimum oxygen content must be ensured at the wall temperature, which defines the oxygen concentration range allowed for operation for a given system. For instance (Figure 1), in the BREST-300 like coolant, the operating conditions are [6]: operating coolant temperature $420-540^{\circ} \mathrm{C}$, maximum fuel clad temperature of $650^{\circ} \mathrm{C}$, and minimum steam generator wall temperature of $200^{\circ} \mathrm{C}$. Thus, the oxygen concentration must be kept lower than 0.01 wt-ppm to prevent coolant oxidation at $200^{\circ} \mathrm{C}$ and higher than 0.0005 wt-ppm to keep 
Post print

Courouau, J. L., et J. C. Robin. « Chemistry control analysis of lead alloys systems to be used as nuclear coolant or spallation target ». Journal of Nuclear Materials 335, no 2 (2004): 264.

https://doi.org/10.1016/j.jnucmat.2004.07.022

oxide protection at $650^{\circ} \mathrm{C}$, that could be compared to the range defined only by the bulk temperatures: $610^{-5}$ wt-ppm $\left(420^{\circ} \mathrm{C}\right)$ to $2 \mathrm{wt}-\mathrm{ppm}\left(540^{\circ} \mathrm{C}\right)$ which is drastically larger. If the same kind of conditions are required for lead coolant, the range of oxygen to ensure no contamination and corrosion protection by iron oxide is $0.31 \mathrm{wt}-\mathrm{ppm}$ at $375^{\circ} \mathrm{C}$ and $2.610^{-3}$ wt-ppm at $650^{\circ} \mathrm{C}$, which is even narrower.

However, the condition that iron is present in saturated condition is foreseeable in static condition, but unlikely in dynamic loop condition where mass transfer will play a role. Indeed, in a non-isothermal system, the iron will be released from the hot structural wall (corrosion), and transferred to locations with lower temperature, where it may precipitate. The diffusion and the convection processes are the 2 mechanisms responsible for the mass transfer: usually, the diffusion of the species from the wall to the liquid bulk (boundary layer) is the limiting process. This latter includes the diffusion through the oxide layer when it is present. The thermodynamic condition for oxide formation on the interface can then be quite different from the condition in the liquid bulk, which is the result of a dynamic equilibrium. Figure 2 illustrates this: decreasing the iron concentration reduces the oxidation area, the higher the temperature the higher the reduction. For working at higher temperature, the oxygen content should then be close to its saturation limit. Indeed, the iron in equilibrium with its oxide at the wall interface can then be several orders of magnitude lower than its solubility, which reduces in turn the corrosion rate to low or very low level. This is the working mechanism behind the active oxygen control and the oxide film formation [13]. In addition, the iron concentration is difficult to measure and impossible to monitor on-line up to now. The lower detection limit is 5 wt-ppm [3] for chemical analysis up to now, and could possibly be lowered to $0.5 \mathrm{wt}-\mathrm{ppm}$, which may still be higher than the iron concentration expected. There is no straight solution to control the iron content, but oxygen should be controlled and monitored on line so that it gives at least the hand on one parameter. As a consequence, the oxygen specification should be set at the highest possible value that complies with the contamination requirement, which corresponds to the cold leg temperature interface, as this is maximizing the oxidation area for an unknown iron concentration. From the previous example, the oxygen concentration chosen would then be $0.01 \mathrm{wt}-\mathrm{ppm}$.

This thermodynamic analysis was made thanks to some assumptions, and could be more or less well applied to perlite steel (Fe 100\%), but might be slightly different for $\mathrm{Cr}$ alloyed steel for instance, as the oxide layer will be a compound of oxides. Real operating limits should be measured on test facilities in representative operating conditions and for relevant materials.

\section{Conclusions}

The main impurity with the largest potential consequences is oxygen, which has to be measured on-line both in the liquid and gas phases, and controlled by specific processes either for oxygen concentration adjustment or for re-achieving a low oxygen activity after pollution to ensure no contamination of the coolant. Nearly all of these systems are under development for a nuclear implementation although their basic use is demonstrated on loops. Basic data are required (actual release rates, diffusivities of oxygen and iron in LBE and in coatings, etc.), especially for any change of scale, to model the oxygen distribution within the system as regards the homogeneity issue, as well as its interactions with other impurities in order to model both corrosion and precipitation phenomena (including $\mathrm{PbO}$ ) together with the flow modeling of the system. 
Post print

Courouau, J. L., et J. C. Robin. "Chemistry control analysis of lead alloys systems to be used as nuclear coolant or spallation target ». Journal of Nuclear Materials 335, no 2 (2004): 264.

https://doi.org/10.1016/j.jnucmat.2004.07.022

The second main impurity is iron, released during the corrosion of the structural materials, as the dissolution rates for the oxide protected structure or for the structure subjected to dissolution in liquid metal, are low but continuous. For the long-term operation of a system operating at relevant nuclear system temperature, it would be compulsory to purify these impurities, and to take provision for any other solid impurities as well. Monitoring is nowadays limited to liquid metal sampling and chemical analysis. An indirect method for iron measurement could be investigated further [14].

The oxygen is then by far the most important impurity, as all others are related to oxygen somehow through various chemical interactions, so that the global impurities analysis should not be separated for too long, and should include the cover gas system as regards the aerosols formation and the active volatile compounds (spallation or fission products).

\section{Acknowledgement}

This work has been performed within the CEA framework of the transmutation studies for nuclear waste radio toxicity reduction, and was supported as well by the $5^{\text {th }}$ European program (TECLA, Technologies for transmutation). The close collaboration and support of $\mathrm{F}$. Balbaud from CEA/SCCME as well as from V. Ghetta from CNRS/LTPCM is here acknowledged.

\section{References}

[1] Technologies for lead alloys, contracts $n^{\circ}$ FIKW-CT-2000-00092, European commission, 5th EURATOM FRAMEWORK PROGRAMME 1998-2002.

[2] D. Warin, Transmutation studies in Europe, Revue générale du nucléaire (RGN) $n^{\circ} 4$, Août-Septembre 2002.

[3] J-L. Courouau, P. Trabuc, G. Laplanche, P. Deloffre, P. Taraud, M. Ollivier, R. Adriano, S. Trambaud, Journal of Nuclear Materials 301 (2002) 53-59.

[4] J-L. Courouau, P. Deloffre, R. Adriano, Journal de Physique IV France 12 (2002), Pr8 $141-153$.

[5] S. Sellier, J-L.Courouau, Recent feedback on sodium quality monitoring and purification from the Phenix reactor, to be issued in Nuclear Technologies.

[6] B.A. Shmatko, A.E. Russanov, Materials Science, vol.36, N5, 2000.

[7] HLMC Proceedings, Obninsk, Russian Federation, Oct. 5-9,1998.

[8] J-L. Courouau, Tritium issue in sodium cooled fast reactors, to be issued in Nuclear Technologies.

[9] F Balbaud-Célérier, C. Delisle, A. Terlain, Proceedings of the 4th MEGAPIE Technical Review Meeting, Paris, France, March 18-19 2003.

[10] IAEA TECDOC-1289, June 2002.

[11] H. U. Borgstedt, C. K. Mathews, Applied chemistry of the liquid alkali metals, Plenum press, New-York-London, 1987.

[12] Chemical reaction and equilibrium software, HSC Outokumpu version 4.1.

[13] N. Li, Journal of Nuclear Material 300 (2002) 73-81. 
Post print

Courouau, J. L., et J. C. Robin. « Chemistry control analysis of lead alloys systems to be used as nuclear coolant or spallation target ». Journal of Nuclear Materials 335, n 2 (2004): 264.

https://doi.org/10.1016/j.jnucmat.2004.07.022

[14] J-L. Courouau, Oxygen sensor development status, same issue. 
Post print

Courouau, J. L., et J. C. Robin. « Chemistry control analysis of lead alloys systems to be used as nuclear coolant or spallation target ». Journal of Nuclear Materials 335, no 2 (2004): 264.

https://doi.org/10.1016/.j.jnucmat.2004.07.022

\section{Figure captions :}

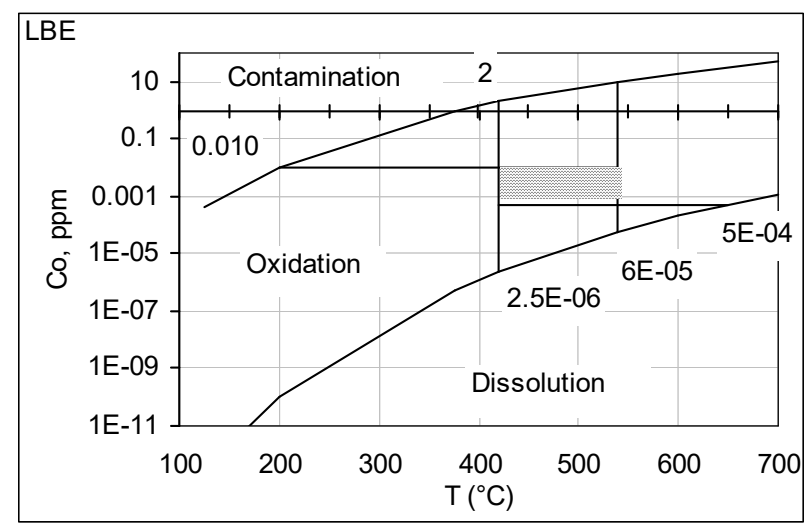

Figure 1: Oxygen range in LBE for a BREST-300 like primary coolant, showing in shaded area the allowable oxygen operating range, as well as the contamination $\left(\mathrm{C}_{0}=\mathrm{C}_{0}{ }^{*}\right)$, the oxidation $\left(\mathrm{C}_{\mathrm{omin}}<\mathrm{C}_{\mathrm{o}}<\mathrm{C}_{\mathrm{o}}{ }^{*}\right)$ and the reduction $\left(\mathrm{C}_{\mathrm{o}}<\mathrm{C}_{\mathrm{omin}}\right)$ areas.

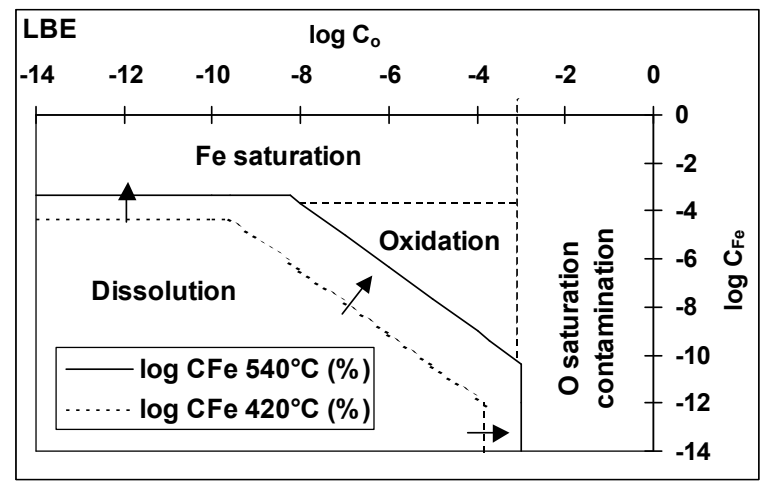

Figure 2: Oxide formation threshold in LBE defining the couple of solution to ensure a protective oxide layer depending on both the iron and oxygen concentrations (weight $\%$ ). 